\title{
Synthesis of Biotinylated Galiellalactone Analogues
}

\author{
Zilma Escobar1, Martin Johansson², Anders Bjartell2, Rebecka Hellsten², Olov Sterner ${ }^{1 *}$ \\ ${ }^{1}$ Centre for Analysis and Synthesis, Department of Chemistry, Lund University, \\ Lund, Sweden \\ ${ }^{2}$ Division of Urological Cancers, Department of Clinical Sciences Malmö, Lund University, \\ Malmö, Sweden \\ Email: olov.sterner@chem.lu.se
}

Received 1 September 2014; revised 16 October 2014; accepted 2 November 2014

Copyright (C) 2014 by authors and Scientific Research Publishing Inc.

This work is licensed under the Creative Commons Attribution International License (CC BY). http://creativecommons.org/licenses/by/4.0/

(c) (i) Open Access

\section{Abstract}

Two biotinylated derivatives of the fungal metabolite galiellalactone (1) were synthesized in order to facilitate the investigation of the molecular mechanism of action of the galiellalactonoids. Galiellalactone is a STAT3-signaling inhibitor that inhibits growth in vitro as well as in vivo of prostate cancer cells expressing activated STAT3. To provide a suitable point of attachment for biotin, the 8-hydroxymethyl derivative (3) and its 7-phenyl analogue 4 were synthesized by a modified tandem Pd-catalysed carbonylation and intramolecular vinyl allene Diels-Alder procedure previously developed. The two primary alcohols obtained, 3 and 4 , were coupled to biotin as the 6-aminohexanoic acid amide, activated as the acid chloride, yielding the derivatives 5 and 6.

\section{Keywords}

STAT3, Galiellalactone, Biotin, Synthesis

\section{Introduction}

The protein STAT3 (Signal Transducer and Activator of Transcription 3) is a transcription factor that is involved in different cellular processes. It has been shown to be constitutively activated in malignancies and is involved in the proliferation of several types of cancer cells [1] [2]. In normal cells, the activation of STAT3 must consequently be tightly regulated, and STAT3 is today considered to be a relevant target for novel drugs for the treatment of cancer [3]. Galiellalactone (1) is a fungal metabolite that inhibits the STAT3 signaling pathway, presumably by reacting covalently with the thiol group of critical cysteines of STAT3 and thereby blocking the

\footnotetext{
${ }^{*}$ Corresponding author.

How to cite this paper: Escobar, Z., Johansson, M., Bjartell, A., Hellsten, R. and Sterner, O. (2014) Synthesis of Biotinylated Galiellalactone Analogues. International Journal of Organic Chemistry, 4, 225-235.

http://dx.doi.org/10.4236/ijoc.2014.44026
} 
binding of STAT3 to STAT3 specific transcriptional DNA elements [4]. 1 inhibits the growth, both in vitro and in vivo, of prostate cancer cells expressing activated STAT3 and inhibits the expression of STAT3 regulated genes and proteins, including anti-apoptotic genes [4]. Furthermore, galiellalactone (1) inhibits growth and induces apoptosis of prostate cancer stem cell-like cells expressing phosphorylated STAT3 (pSTAT3) [5], and has the potential to be developed into a drug for treating cancers in which STAT3 is activated.

1 contains an $\alpha, \beta$-unsaturated lactone moiety, and it has been demonstrated to react with sulfur nucleophiles to produce inactive adducts [6] [7]. It has been proposed that $\mathbf{1}$ interferes directly with the binding of STAT3 to DNA by reacting with a thiol group of a cysteine in STAT3 that is located in a domain of STAT3 that is involved in the binding to DNA [4], however, no evidence supporting this molecular mechanism of action has yet been presented. Target identification and mechanism of action elucidation are highly challenging yet crucial areas of chemistry and biology, and several methods and strategies have been developed to achieve this. Compounds that covalently react with their target provide an advantage as they can be modified or tagged with moieties that allow for the detection or isolation of the compound-target adducts. Biotin labeling of covalent inhibitors is an effective method for detecting and isolating bound target proteins because of the high affinity biotin displays to streptavidin allowing the capture and detection of biotin labeled inhibitor-target adducts. A main challenge is to attach the biotin label to the inhibitor in such a way that the target affinity is not abolished. We envisioned that a hydroxymethyl group in position 8 of $\mathbf{1}$ (see Figure 1) would allow us to attach a biotin group via a suitable linker so that the STAT3 inhibiting effect was retained. To this end, 8-hydroxymethyl-galiellalactone (3) as well as 8-hydroxymethyl-7-phenyl galiellalactone (4) was prepared by a modified tandem Pd-catalysed carbonylation and intramolecular vinyl allene Diels-Alder strategy previously developed for the synthesis of 4-epi-1 [8]. 3 and $\mathbf{4}$ were then coupled with an ester bond to the 6-aminohexanoic acid amide of biotin, yielding the two desired compounds 5 and $\mathbf{6}$ (Figure 1). Both enantiomers of galiellalactone (1) have been prepared [9] [10] and found to be an equally potent inhibitors of IL-6 mediated STAT3 signaling [7] [11], consequently 3 and $\mathbf{4}$ were prepared as racemates while $\mathbf{5}$ and $\mathbf{6}$ were obtained as pairs of diastereomers. During our work with analogues of $\mathbf{1}$ [8], we had indications (unpublished results) that a substituent in position 7 was beneficial for the potency, and to investigate if a phenyl group at C-7 affects the STAT3 inhibiting effect of galiellalactone (1) the 7-phenyl analogue 2 was prepared and assayed.

\section{Experimental Section}

Reagents and solvents were used from commercial sources without purification, except THF and $\mathrm{CH}_{2} \mathrm{Cl}_{2}$ that were passed through a MBraun SPS-800 solvent system. All reactions were carried out in standard dry glassware and atmospheric surroundings. Analytical thin layer chromatography (TLC) was performed on Kiselgel 60 F254 plates (Merck) and visualized by spraying with vanillin/ $\mathrm{H}_{2} \mathrm{SO}_{4}$ and heating. Silica gel column chromatography was performed on $\mathrm{SiO}_{2}$ (Matrex LC-gel: 60A, 35-70 MY, Grace). ${ }^{1} \mathrm{H}$ and ${ }^{13} \mathrm{C}$ NMR spectra were rec-

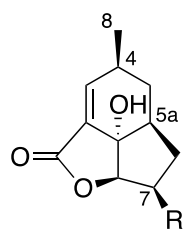

$$
1 \mathrm{R}=\mathrm{H}
$$

$2 \mathrm{R}=\mathrm{Ph}$

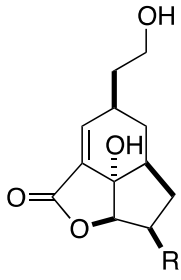

$$
3 \mathrm{R}=\mathrm{H}
$$$$
4 \mathrm{R}=\mathrm{Ph}
$$

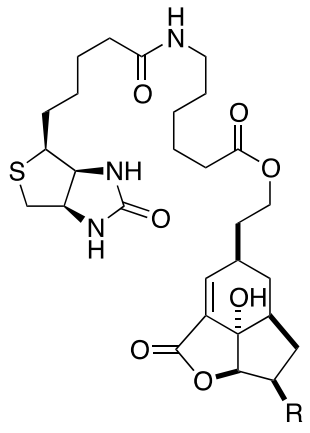

$5 \mathrm{R}=\mathrm{H}$

Figure 1. Structures of the fungal metabolite galiellalactone (1), (+)-7-phenyl galiellalactone (2), the two analogues 8-hydroxymethyl galiellalactone (3) and 8-hydroxymethyl-7-phenyl galiellalactone (4), and the corresponding $N$ (+)-biotinyl-6-aminohexanoic acid esters 5 and $\mathbf{6}$. 
orded with a Bruker DRX 400 spectrometer (at $400 \mathrm{MHz}$ for ${ }^{1} \mathrm{H}$ and $100 \mathrm{MHz}$ for ${ }^{13} \mathrm{C}$ ) and a Bruker DRX 500 spectrometer (at 500 and $125 \mathrm{MHz}$, respectively). The spectra were recorded in $\mathrm{CDCl}_{3}$ and $\mathrm{CD}_{3} \mathrm{OD}$, and the solvent signals (7.27/77.0 and 3.31/49.0 ppm) were used as reference. The data for the ${ }^{1} \mathrm{H}$ signals are given as chemical shifts in ppm and (number of protons, multiplicity, and coupling constants $(J)$ in $\mathrm{Hz}$ ), while the ${ }^{13} \mathrm{C}$ data are given as chemical shifts in ppm. HR-ESIMS spectra were recorded with a Waters Q-TOF Micro system.

Hept-6-en-1-yn-3-ol(8a): To a solution of ethynyl magnesium bromide (100 ml, $0.5 \mathrm{M}$ in THF, $50 \mathrm{mmol})$ was slowly added to a solution of 4-pentenal $(7 \mathbf{a}, 3.70 \mathrm{~g}, 44.0 \mathrm{mmol})$ in $54 \mathrm{ml}$ of dried THF at $0^{\circ} \mathrm{C}$. After the addition was complete, the solution was allowed to reach room temperature and stirred overnight. The reaction mixture was quenched by the addition of $50 \mathrm{ml} \mathrm{NH}_{4} \mathrm{Cl}$ (sat.), the mixture was extracted 3 times with $80 \mathrm{ml}$ EtOAc and the organic phase was dried with $\mathrm{MgSO}_{4}$ and concentrated under reduced pressure. 8a was obtainedas a yellowish oil (4.75 g, quantitative yield), which was used without further purification in the next step. ${ }^{1} \mathrm{H}$ NMR (400 MHz, $\left.\mathrm{CDCl}_{3}\right) 5.69$ (1 H, ddt, 17.1, 10.2, 6.7), 4.93 (1 H, ddd, 17.1, 3.4, 1.5), 4.85 (1 H, ddd, 10.2, 3.4, 1.5), 4.25 (1 H, td, 6.7, 2.1), $2.37(1 \mathrm{H}, \mathrm{d}, 2.1), 2.10(2 \mathrm{H}, \mathrm{m}), 1.67(2 \mathrm{H}, \mathrm{m}) .{ }^{13} \mathrm{C}$ NMR $\left(100 \mathrm{MHz}, \mathrm{CDCl}_{3}\right) 137.5$, 115.4, 84.6, 73.2, 61.7, 36.6, 29.2. HRMS calcd for $\mathrm{C}_{7} \mathrm{H}_{11} \mathrm{O}[\mathrm{M}+\mathrm{H}]$ : 111.0810, found: 111.0834 .

4-Phenylhept-6-en-1-yn-3-ol(8b): Phenylacetic acid (30.0 g, $220 \mathrm{mmol})$ was dissolved in $100 \mathrm{ml} \mathrm{MeOH}$ and $\mathrm{SOCl}_{2}(28.8 \mathrm{~g}, 242 \mathrm{mmol})$ was added dropwise at $0^{\circ} \mathrm{C}$ under stirring. The reaction mixture was allowed to reach room temperature overnight and the volatiles were removed under reduced pressure. Phenylacetic acid methyl ester was obtained as a yellowish oil (32.8 g, quantitative yield) and used directly in the next step. ${ }^{1} \mathrm{H}$ NMR (400 $\left.\mathrm{MHz}, \mathrm{CDCl}_{3}\right) 7.34(5 \mathrm{H}, \mathrm{m}), 3.72(3 \mathrm{H}, \mathrm{s}), 3.67(2 \mathrm{H}, \mathrm{s}) .{ }^{13} \mathrm{C}$ NMR $\left(100 \mathrm{MHz}, \mathrm{CDCl}_{3}\right)$ 171.0, 133.6, 128.6, 127.8, 126.3, 51.0, 40.2. HRMS calcd for $\mathrm{C}_{9} \mathrm{H}_{10} \mathrm{O}_{2} \mathrm{Na}$ [M + Na]: 173.0578, found: 173.0558. Phenylacetic acid methyl ester ( $14.0 \mathrm{~g}, 93 \mathrm{mmol}$ ) was dissolved in $150 \mathrm{ml}$ dry THF and added slowly at $-78^{\circ} \mathrm{C}$ over $30 \mathrm{~min}$ to a freshly prepared LDA solution [12] $3 \mathrm{~g}, 120 \mathrm{mmol}$, diisopropyl amine and $67 \mathrm{ml}, 107 \mathrm{mmol}$, of n-BuLi (1.6 M in hexane)]. The reaction mixture was stirred for $30 \mathrm{~min}$ at $-78^{\circ} \mathrm{C}$ before allyl bromide $(17.0 \mathrm{~g}, 141 \mathrm{mmol})$ was

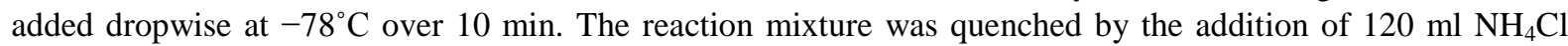
(sat.), extracted 3 times with $100 \mathrm{ml}$ EtOAc, the combined organic phases were dried $\left(\mathrm{MgSO}_{4}\right)$ and concentrated by evaporation to afford methyl 2-phenylpent-4-enoate as a yellowish oil (17.7 g, quantitative yield). ${ }^{1} \mathrm{H}$ NMR (400 MHz, $\left.\mathrm{CDCl}_{3}\right) 7.27(3 \mathrm{H}, \mathrm{m}), 7.22(2 \mathrm{H}, \mathrm{m}), 5.68(1 \mathrm{H}, \mathrm{ddt}, 17.0,10.2,6.8), 5.04$ (1 H, ddd, 17.0, 2.9, 1.3), 4.96 (1 H, ddt, 10.2, 2.9, 1.3), $3.61(1 \mathrm{H}, \mathrm{t}, 7.8), 3.61(3 \mathrm{H}, \mathrm{s}), 2.80(1 \mathrm{H}, \mathrm{m}), 2.48(1 \mathrm{H}, \mathrm{m}) .{ }^{13} \mathrm{C}$ NMR $(100 \mathrm{MHz}$, $\mathrm{CDCl}_{3}$ ) 173.8, 138.5, 135.2, 128.6, 127.8, 127.3, 116.9, 51.9, 51.3, 37.5. HRMS calcd for $\mathrm{C}_{12} \mathrm{H}_{14} \mathrm{O}_{2} \mathrm{Na}[\mathrm{M}+\mathrm{Na}$ : 213.0891, found: 213.0891. Methyl 2-phenylpent-4-enoate $(8.7 \mathrm{~g}, 46 \mathrm{mmol})$ in $200 \mathrm{ml}$ of dry $\mathrm{CH}_{2} \mathrm{Cl}_{2}$ was reduced to $7 \mathbf{b}$ by slowly adding DIBAL-H $(48.0 \mathrm{ml}, 1 \mathrm{M}$ in hexane, $48.0 \mathrm{mmol})$ under $\mathrm{N}_{2}$ atmosphere at $-78^{\circ} \mathrm{C}$ and stirring for $3 \mathrm{~h}$ at $-78^{\circ} \mathrm{C}$. Without work-up and purification, ethynyl magnesium bromide (100 $\mathrm{ml}, 0.5 \mathrm{M}$ in THF, $50 \mathrm{mmol}$ ) was added dropwise to the reaction mixture which was stirred for an additional $30 \mathrm{~min}$ at $-78^{\circ} \mathrm{C}$ and left at room temperature overnight before the reaction was quenched by the addition of $120 \mathrm{ml} \mathrm{NaHCO}_{3}$ (sat.). The mixture was extracted 4 times with $80 \mathrm{ml}$ EtOAc and the combined organic phases were dried with $\mathrm{MgSO}_{4}$ and concentrated by evaporation. The crude product was purified by silica gel chromatography, and $\mathbf{8 b}$ ( $3.5 \mathrm{~g}$, 41\%) was obtained as a 1:0.2 mixture of diastereomers. Diastereomer a) ${ }^{1} \mathrm{H}$ NMR $\left(400 \mathrm{MHz}, \mathrm{CDCl}_{3}\right) 7.24(5 \mathrm{H}$, m), 5.64 (1 H, ddd, 17.0; 10.1, 6.2), 5.03 (1 H, ddd, 17.0, 3.1, 1.3), 4.93 (1 H, ddt, 10.1, 3.1, 1.3), 4.48 (1 H, dd, 8.5, 2.2), $2.94(1 \mathrm{H}, \mathrm{dt}, 8.5,6.2), 2.65(1 \mathrm{H}, \mathrm{m}), 2.52(1 \mathrm{H}, \mathrm{m}), 2.39(1 \mathrm{H}, \mathrm{d}, \mathrm{J} 2.2) .{ }^{13} \mathrm{C}$ NMR $\left(100 \mathrm{MHz}, \mathrm{CDCl}_{3}\right)$ 139.1, 135.8, 129.1, 128.0, 127.0, 116.6, 82.8, 74.9, 65.3, 50.8, 35.2. Diastereomer b) ${ }^{1} \mathrm{H}$ NMR (400 MHz, $\left.\mathrm{CDCl}_{3}\right) 7.24(5 \mathrm{H}, \mathrm{m}), 5.64$ (1 H, ddd, 17.0; 10.1, 6.2), 5.03 (1 H, ddd, 17.0, 3.1, 1.3), 4.93 (1 H, ddt, 10.1, 3.1, 1.3), 4.48 (1 H, ddd, 8.5, 2.2), $2.92(1 \mathrm{H}, \mathrm{dt}, 8.5,6.2), 2.67(1 \mathrm{H}, \mathrm{m}), 2.52(1 \mathrm{H}, \mathrm{m}), 2.43(1 \mathrm{H}, \mathrm{d}, 2.2) .{ }^{13} \mathrm{C} \mathrm{NMR}$ (100 MHz, $\mathrm{CDCl}_{3}$ ) 139.2, 135.9, 128.8, 128.2, 126.9, 116.7, 83.2, 74.6, 65.5, 51.4, 35.1. HRMS calcd for $\mathrm{C}_{13} \mathrm{H}_{14} \mathrm{ONa}[\mathrm{M}+\mathrm{Na}]$ : 209.0942, found: 209.0919.

(Z)-11-((Triisopropylsilyl)oxy)undeca-1,8-dien-6-yn-5-ol(10a): TEA (55 ml, $400 \mathrm{mmol})$ was added to a mixture of $\mathrm{PdCl}_{2}\left(\mathrm{PPh}_{3}\right)_{2}(0.70 \mathrm{~g}, 0.99 \mathrm{mmol})$ and $\mathrm{CuI}(0.38 \mathrm{~g}, 1.99 \mathrm{mmol})$ at $0{ }^{\circ} \mathrm{C}$ under nitrogen atmosphere and the solution was stirred for 30 minutes. To this solution 9 (7.25 g, $20.5 \mathrm{mmol})$, prepared according to reference 12 and identical in all aspects with the reported compound, in $40 \mathrm{ml}$ dry THF was added dropwise followed by $\mathbf{8 a}$ ( $2.19 \mathrm{~g}, 20.0 \mathrm{mmol}$ ) in $40 \mathrm{ml}$ dry $\mathrm{THF}$ at $0^{\circ} \mathrm{C}$. The reaction mixture was stirred overnight at room temperature, quenched with $50 \mathrm{ml} \mathrm{NaHCO}$ (sat.), extracted 3 times with $60 \mathrm{ml}$ EtOAc. The combined organic phases were dried with $\mathrm{Na}_{2} \mathrm{SO}_{4}$ and concentrated by evaporation. The yield was quantitative and 10a was used directly in the next step without purification. ${ }^{1} \mathrm{H}$ NMR $\left(400 \mathrm{MHz}, \mathrm{CDCl}_{3}\right) 6.04(1 \mathrm{H}, \mathrm{dt}, 10.8,7.0), 5.85(1 \mathrm{H}$, ddt, 17.0, 10.2, 7.2), 5.56 (1 H, ddd, 10.8, 3.1, 1.4), 5.08 (1 H, ddd, 17.0, 3.2, 1.5), 5.00 (1 H, dd, 10.2, 3.2), 4.54 (1 H, td, 6.5, 
3.1), 3.76 (2 H, t, 7.0), 2.56 (2 H, qd, J 7.0, 1.4), 2.26 (2 H, td, J 7.2, 1.5), 1.83 (2 H, m), 1.13 - 1.03 (21 H, m). ${ }^{13} \mathrm{C}$ NMR (100 MHz, $\mathrm{CDCl}_{3}$ ) 141.1, 137.9, 115.5, 110.0, 94.4, 82.1, 62.7, 62.5, 37.1, 34.4, 29.7, $18.2,12.2$. HRMS calcd for $\mathrm{C}_{20} \mathrm{H}_{37} \mathrm{O}_{2} \mathrm{Si}[\mathrm{M}+\mathrm{H}]$ : 337.2563, found: 337.2560.

(Z)-Methyl (11-((triisopropylsilyl)oxy)undeca-1,8-dien-6-yn-5-yl) carbonate(11a): 10a (6.70 g, $20.0 \mathrm{mmol})$ was dissolved in $130 \mathrm{ml}$ of dry $\mathrm{CH}_{2} \mathrm{Cl}_{2}$ at $0^{\circ} \mathrm{C}$. DMAP (4.86 g, $39.8 \mathrm{mmol}$ ) was added and the mixture was stirred for $20 \mathrm{~min}$. Methyl chloroformate (5.6 g, $59.7 \mathrm{mmol}$ ) was added dropwise, and the reaction was brought to room temperature overnight before $50 \mathrm{ml} \mathrm{NaHCO}_{3}$ (sat.) was added and the mixture was extracted 2 times with $80 \mathrm{ml} \mathrm{CH}_{2} \mathrm{Cl}_{2}$. The combined organic phases were dried over $\mathrm{MgSO}_{4}$ and concentrated under reduced pressure. The crude product was purified by flash chromatography with $\mathrm{CH}_{2} \mathrm{Cl}_{2}$ /heptane $1: 1$ as eluent, giving $3.59 \mathrm{~g}(46 \%)$ of 11a as a yellowish oil. ${ }^{1} \mathrm{H}$ NMR (400 MHz, CDCl $) 6.09(1 \mathrm{H}, \mathrm{dt}, 10.8,7.3), 5.82$ (1 H, ddt, 17.0, 10.2, 6.6), 5.56 (1 H, ddd, 10.8, 3.3, 1.7), 5.40 (1 H, td, 6.6, 1.7), 5.07 (1 H, ddd, 17.0, 3.2, 1.3), 5.02 (1 H, ddd, 10.2, 3.2, 1.3), 3.81 (3 H, s), 3.76 (2 H, t, 6.5), 2.55 (2 H, qd, 6.6, 1.3), 2.25 (2 H, m), 1.95 (2 H, m), 1.09 1.03 (21 H, m). ${ }^{13} \mathrm{C}$ NMR (100 MHz, $\mathrm{CDCl}_{3}$ ) 155.2, 142.3, 137.0, 115.9, 109.6, 89.9, 83.7, 68.5, 62.5, 55.1, 34.4, 34.3, 29.4, 18.2, 12.2. HRMS calcd for $\mathrm{C}_{22} \mathrm{H}_{39} \mathrm{O}_{4} \mathrm{NaSi}[\mathrm{M}+\mathrm{H}]$ : 395.2618, found: 395.2647 .

(Z)-4-Phenyl-11-((triisopropylsilyl)oxy)undeca-1,8-dien-6-yn-5-ol(10b):10b was prepared in the same way as 10a, from $\mathbf{8 b}$, and $\mathbf{1 0 b}$ was obtained in a quantitative yield as a 1:0.2 mixture of diastereomers. Diastereomer a) ${ }^{1} \mathrm{H}$ NMR (400 MHz, $\left.\mathrm{CDCl}_{3}\right) 7.30$ (5 H, m), 6.05 (1 H, dt, 10.8, 7.4), 5.71 (1 H, ddt, 17.1, 10.2, 6.3$), 5.55$ (1 H, ddd, 10.8, 3.3, 1.5), 5.08 (1 H, ddd, 17.1, 3.2, 1.6), 4.99 (1 H, ddd, 10.2, 3.2, 1.6), 4.74 (1 H, ddd, 7.5, 5.7, 1.5), 3.74 (2 H, t, 6.5), 3.04 (1 H, m), 2.65 (2 H m), 2.51 (2 H, m), 1.77 (1 H, d, 7.5), 1.17 - 1.04 (21 H, m). ${ }^{13} \mathrm{C} \mathrm{NMR}$ (100 $\mathrm{MHz}_{\mathrm{CDCl}}$ ) 141.2, 139.4, 136.1, 129.2, 128.2, 127.2, 116.7, 109.6, 92.4, 83.8, 66.4, 62.4, 51.4, 35.6, 34.1, 18.0, 12.0. Diastereomer b) ${ }^{1} \mathrm{H}$ NMR (400 MHz, $\left.\mathrm{CDCl}_{3}\right) 7.30(5 \mathrm{H}, \mathrm{m}), 6.03$ (1 H, dt, 10.8, 7.4), 5.71 (1 H, ddt, 17.1, 10.2, 6.3), 5.57 (1 H, ddd, 10.8, 3.3, 1.5), 5.06 (1 H, ddd, 17.1, 3.2, 1.6), 4.99 (1 H, ddd, 10.2, 3.2, 1.6), 4.77 (1 H, ddd, 7.5, 5.7, 1.5), 3.78 (2 H, t, 6.5), 3.01 (1 H, m), 2.70 (2 H m), 2.51 (2 H, m), 1.78 (1 H, d, 7.5$)$, 1.17 - $1.04(21 \mathrm{H}, \mathrm{m}) .{ }^{13} \mathrm{C}$ NMR $\left(100 \mathrm{MHz} \mathrm{CDCl}_{3}\right)$ 141.3, 139.6, 136.2, 128.9, 128.4 127.1, 116.8, 109.7, 92.8, 83.5, 66.5, 62.4, 52.1, 35.6, 34.2, 18.0, 12.0.HRMS calcd for $\mathrm{C}_{26} \mathrm{H}_{40} \mathrm{O}_{2} \mathrm{NaSi}[\mathrm{M}+\mathrm{Na}$ ]: 435.2695, found: 435.2663.

(Z)-Methyl (4-phenyl-11-((triisopropylsilyl)oxy)undeca-1,8-dien-6-yn-5-yl) carbonate(11b):11b was prepared in the same way as 11a, from 10b, and 11b was obtained in a 75\% yield as a 1:0.2 mixture of diastereomers. Diastereomer a) ${ }^{1} \mathrm{H}$ NMR (400 MHz, $\left.\mathrm{CDCl}_{3}\right) 7.28$ (5 H, m), 6.04 (1 H, dt, 11.5, 6.9), 5.65 (1 H, ddd, 17.1, 10.9, 6.7), 5.58 (1 H, dd, 4.8, 2.1), 5.48 (1 H, ddd, 11.5, 2.1, 1.6), 5.04 (1 H, ddd, 17.1, 3.2, 1.5), 4.96 (1 H, ddd, 10.9 , 3.2, 1.5), 3.78 (3 H, s), 3.68 (2 H, t, 6.4), 3.15 (1 H, m), 2.71 (1 H, m), 2.56 (1 H, m), 2.37 (2 H, dtd, 6.9, 6.4, 1.6), 1.17 - 0.95 (21 H, m). ${ }^{13} \mathrm{C}$ NMR (100 MHz, $\left.\mathrm{CDCl}_{3}\right)$ 154.9, 142.1, 139.2, 135.4, 128.8, 128.2, 127.1, 117.0, 109.2, 88.5, 84.6, 71.7, 62.3, 54.9, 49.4, 35.5, 34.0, 18.0, 11.9. Diastereomer b) ${ }^{1} \mathrm{H}$ NMR (400 $\left.\mathrm{MHz}^{\mathrm{C}} \mathrm{CDCl}_{3}\right)$ 7.28 (5 H, m), 6.06 (1 H, dt, 11.5, 6.9), 5.66 (1 H, ddd, 17.1, 10.9, 6.7), 5.58 (1 H, dd, 4.8, 2.1), 5.50 (1 H, ddd, 11.5, 2.1, 1.6), 5.05 (1 H, ddd, 17.1, 3.2, 1.5), 4.97 (1 H, ddd, 10.9, 3.2, 1.5), 3.76 (3 H, s), 3.70 (2 H, t, 6.4$)$, 3.15 (1 H, m), 2.73 (1 H, m), 2.57 (1 H, m), 2.50 (2 H, dtd, 6.9, 6.4, 1.6), 1.17 - 0.95 (21 H, m). ${ }^{13} \mathrm{C} \mathrm{NMR}(100$ $\mathrm{MHz}_{\mathrm{CDCl}}$ ) 154.8, 142.3, 138.9, 135.2, 128.8, 128.2, 127.1, 116.9, 109.3, 88.46, 84.7, 71.8, 62.3, 54.8, 49.7, 34.9, 34.1, 18.0, 11.9. HRMS calcd for $\mathrm{C}_{28} \mathrm{H}_{42} \mathrm{O}_{4} \mathrm{NaSi}[\mathrm{M}+\mathrm{Na}]$ : 493.2750, found: 493.2773 .

rac-(6R,7aR)-Methyl 6-(2-((triisopropylsilyl)oxy)ethyl)-2,6,7,7a-tetrahydro- $1 H$-indene-4-carboxylate(12a): To a dried autoclave flask was added Pd(OAc) $2(0.41 \mathrm{~g}, 1.8 \mathrm{mmol})$ and DPPP (0.75 g, $1.8 \mathrm{mmol})$ under a nitrogen atmosphere, followed by $9 \mathrm{ml}$ dry toluene and 11a (3.59 g, $9.1 \mathrm{mmol})$ dissolved in $9 \mathrm{ml}$ toluene/MeOH (1:1). CO was bubbled though the solution before the autoclave was pressurized with CO to 5 bar. The reaction mixture was stirred for $48 \mathrm{~h}$ at 5 bar at room temperature before being diluted with 15 ml EtOAc and filtered through a celite plug. The filtered solution was concentrated and purified by silica gel chromatography with heptane/ $\mathrm{Et}_{2} \mathrm{O}(94: 6)$ to afford $0.55 \mathrm{~g}(16 \%)$ of $\mathbf{1 2 a}$ as a colourless oil. ${ }^{1} \mathrm{H}$ NMR (400 MHz, $\left.\mathrm{CDCl}_{3}\right) 6.82(1 \mathrm{H}, \mathrm{d}$, 2.1), 6.27 (1 H, dd, 6.1, 2.6), 3.82 (2 H, m), 3.78 (3 H, s), 2.73 (1 H, m), 2.72 (1 H, dddd, 16.4, 8.8, 5.2, 2.1), 2.44 (2 H, ddd, 11.5, 4.5, 2.6), 2.14 (1 H, m), 2.12 (1 H, m), 1.77 (1 H, td, 13.5, 6.6), 1.60 (1 H, td, 13.5, 5.2), 1.37 (1 H, ddd, 12.5, 11.5, 3, 6.1), 1.10 (1 H, m), $1.08-1.04(21 \mathrm{H}, \mathrm{m}) .{ }^{13} \mathrm{C}$ NMR (100 MHz, CDCl $) 167.2$, 145.7, 137.8, 127.0, 126.9, 61.2, 51.7, 44.7, 38.6, 36.4, 35.2, 32.4, 31.2, 18.2, 12.2. HRMS calcd for $\mathrm{C}_{22} \mathrm{H}_{38} \mathrm{O}_{3} \mathrm{NaSi}[\mathrm{M}+\mathrm{Na}]:$ 401.2518, found: 401.2488 .

Methyl 2-phenyl-6-(2-((triisopropylsilyl)oxy)ethyl)-2,6,7,7a-tetrahydro-1H-indene-4-carboxylate(12b):12b was prepared in the same way as 12a, starting from $\mathbf{1 1 b}(6.55 \mathrm{~g}, 13.9 \mathrm{mmol})$. 12b was obtained as colourless oil as a 1:0.8 inseparable mixture of two diastereomers (total yield 2.64 g, 42\%). Diastereomer a) ${ }^{1} \mathrm{H} \mathrm{NMR}$ (400 MHz, 
$\left.\mathrm{CDCl}_{3}\right) 7.24$ (5 H, m), 6.94 (1 H, t, 2.5), 6.32 (1 H, m), 4.02 (1 H, m), 3.85 (2 H, m), 3.79 (3 H, s), 2.86 (1 H, m), 2.75 (1 H, m), 2.60 (1 H, dt, 12.3, 7.0), 2.16 (1 H, dd, 10.2, 2.5), 2.00 (1 H, dt, 10.2, 9.2), 1.81 (1 H, tt, 13.2, 6.5), 1.65 (1 H, dt, 13.2, 6.5), 1.37 (1 H, dt, 12.3, 10.2), $1.21-0.91$ (21 H, m). $\left.{ }^{13} \mathrm{C} \mathrm{NMR} \mathrm{(100} \mathrm{MHz,} \mathrm{CDCl}\right) 166.9$, 146.8, 146.0, 138.3, 130.4, 129.4, 128.4, 127.5, 126.6, 126.1, 60.9, 51.6, 51.3, 50.3, 44.6, 43.2, 42.2, 39.8, 38.4, 36.2, 35.2, 18.0, 12.0. Diastereomer b) ${ }^{1} \mathrm{H}$ NMR (400 MHz, $\left.\mathrm{CDCl}_{3}\right) 7.24(5 \mathrm{H}, \mathrm{m}), 6.40$ (1 H, m), 6.32 (1 H, m), 4.02 (1 H, m), 3.85 (2 H, m), 3.78 (3 H, s), 2.96 (1 H, m), 2.75 (1 H, m), 2.60 (1 H, dt, 12.3, 7.0), 2.16 (1 H, dd, 10.2, 2.5), 2.00 (1 H, dt, 10.2, 9.2), 1.81 (1 H, tt, 13.2, 6.5), 1.61 (1 H, m), 1.37 (1 H, dt, 12.3, 10.2$), 1.21$ - 0.91 (21 H, m). ${ }^{13} \mathrm{C}$ NMR (100 MHz, $\left.\mathrm{CDCl}_{3}\right)$ 166.9, 146.7, 145.6, 138.4, 130.4, 129.3, 128.4, 127.2, 126.6, 126.0, 60.9, 51.6, 51.3, 50.3, 44.6, 43.2, 42.2, 39.8, 38.3, 36.1, 35.0, 18.0, 12.0. HRMS calcd for $\mathrm{C}_{28} \mathrm{H}_{43} \mathrm{O}_{3} \mathrm{Si}[\mathrm{M}+\mathrm{H}]$ : 455.2981, found: 455.2956.

rac-(1aS,3aR,5R,7aS)-Methyl 5-(2-((triisopropylsilyl)oxy)ethyl)-1a,2,3,3a,4,5-hexahydroindeno [1,7a-b]oxirene-7-carboxylate(13a): 12a (0.55 g, $1.4 \mathrm{mmol})$ was dissolved in $30 \mathrm{ml}$ dry $\mathrm{CH}_{2} \mathrm{Cl}_{2}$ under nitrogen atmosphere and $\mathrm{m}$-CPBA $(0.32 \mathrm{~g}, 1.9 \mathrm{mmol})$ was added at $0^{\circ} \mathrm{C}$. The reaction mixture was stirred at this temperature for $1 \mathrm{~h}$ before it was quenched by the addition of $10 \mathrm{ml} \mathrm{Na}{ }_{2} \mathrm{~S}_{2} \mathrm{O}_{3}$ (sat.). The phases were separated and organic phase was washed with $\mathrm{NaHCO}_{3}$ (sat.). The water phases were extracted with 3 times with $20 \mathrm{ml}$ dry $\mathrm{CH}_{2} \mathrm{Cl}_{2}$ and the combined organic phases were dried over $\mathrm{Na}_{2} \mathrm{SO}_{4}$, filtered and evaporated. Flash chromatography $\left(\mathrm{SiO}{ }_{2}\right.$, heptane/ $\left.\mathrm{Et}_{2} \mathrm{O} 85: 15\right)$ afforded the required isomer 13a as a colourless oil in $79 \%(0.45 \mathrm{~g})$ yield. ${ }^{1} \mathrm{H} \mathrm{NMR}(400 \mathrm{MHz}$, $\left.\mathrm{CDCl}_{3}\right) 7.29$ (1 H, d, 2.5), 4.41 (1 H, s), 3.84 (2 H, m), 3.72 (3 H, s), 2.70 (1 H, dddd, 16.5, 8.3, 6.1, 2.5), 2.05 (1 H, dd, 13.9, 7.2), 1.97 (1 dddd, 16.5, 13.2, 6.8, 3.3), 1.89 (1 H, m), 1.83 (1 H, ddd, 13.2, 7.2, 5.3), 1.66 (1 H, m), 1.62 (1 H, s), 1.58 (1 H, m), 1.30 (1 H, td, 13.2, 8.3), $1.12(1 \mathrm{H}, \mathrm{m}), 1.08-1.04(21 \mathrm{H}, \mathrm{m}) .{ }^{13} \mathrm{C} \mathrm{NMR}(100 \mathrm{MHz}$ $\left.\mathrm{CDCl}_{3}\right)$ 165.4, 153.9, 126.3, 63.6, 63.3, 60.7, 51.5, 39.7, 38.0, 35.8, 30.1, 27.5, 23.2, 18.0, 11.9. HRMS calcd for $\mathrm{C}_{22} \mathrm{H}_{38} \mathrm{O}_{4} \mathrm{NaSi}[\mathrm{M}+\mathrm{Na}]:$ 417.2437, found: 417.2413.

rac-(1aS,2S,3aS,5R,7aS)-Methyl 2-phenyl-5-(2-((triisopropylsilyl)oxy)ethyl)-1a,2,3,3a,4,5-hexahydroindeno [1,7a-b]oxirene-7-carboxylate(13b): $\mathbf{1 3 b}$ was prepared in the same way as 13a, starting from $12 \mathbf{b}$ (2.64 g, 5.8 mmol). The crude product (2.71 g) was purified by flash chromatography $\left(\mathrm{SiO}_{2}\right.$, heptane/Et ${ }_{2} \mathrm{O}$ 85:15). 13b was obtained as a colourless oil (0.43 g, 16\%). ${ }^{1} \mathrm{H}$ NMR (400 MHz, $\left.\mathrm{CDCl}_{3}\right) 7.42$ (2 H, dd, 8.2, 1.3), 7.34 (1 H, d, 0.9), 7.31 (2 H, td, 8.2, 7.3), 7.24 (1 H, td, 7.3, 1.3), 4.57 (1 H, s), 3.85 (2 H, m), 3.72 (3 H, s), 3.16 (1 H, dd, 12.1, 7.2), 2.75 (1 H, m), 2.12 (1 H, m), 2.04 (1 H, m), 1.92 (1 H, dt, 12.1, 7.2), 1.86 (1 H, dt, 15.2, 6.8$), 1.67$ (1 $\mathrm{H}$, ddd, 15.2, 10.8, 6.8), 1.42 (1 H, m), 1.32 (1 H, dd, 12.1, 11.5), $1.17-1.03(21 \mathrm{H}, \mathrm{m}) .{ }^{13} \mathrm{C} \mathrm{NMR}(100 \mathrm{MHz}$ $\left.\mathrm{CDCl}_{3}\right)$ 165.4, 154.1, 141.6, 128.4, 127.7, 126.6, 126.1, 66.9, 62.3, 60.6, 51.6, 45.9, 40.2, 38.0, 35.6, 32.3, 30.0, 18.0, 12.0. HRMS calcd for $\mathrm{C}_{28} \mathrm{H}_{42} \mathrm{O}_{4} \mathrm{SiNa}[\mathrm{M}+\mathrm{Na}]$ : 493.2750, found: 493.2773 .

rac-(2aS,4R,5aR,7a $R)$-2a-Hydroxy-4-(2-hydroxyethyl)-4,5,5a,6,7,7a-hexahydroindeno [1,7-bc]furan-2(2aH)one(3): 13a (0.45 g, $1.2 \mathrm{mmol})$ was dissolved in $5 \mathrm{ml}$ THF and a solution of $\mathrm{LiOH} \cdot \mathrm{H}_{2} \mathrm{O}(0.12 \mathrm{~g}, 2.8 \mathrm{mmol})$ in 5 $\mathrm{ml} \mathrm{H}_{2} \mathrm{O}$ was added at room temperature. The reaction mixture was stirred for 3 days until a TLC analysis revealed that the starting material was consumed. After the addition of $5 \mathrm{ml}$ THF and $5 \mathrm{ml}$ of $\mathrm{H}_{2} \mathrm{SO}_{4}(10 \%)$, the mixture was stirred at room temperaturefor 3 days. The reaction mixture was quenched by the addition of $3 \mathrm{ml}$ $\mathrm{NaHCO}_{3}$ (sat.) and extracted 3 times with $20 \mathrm{ml}$ EtOAc, the combined organic phases were dried with $\mathrm{Na}_{2} \mathrm{SO}_{4}$ and concentrated by evaporation. The crude product was purified by chromatography $\left(\mathrm{SiO}_{2}, \mathrm{CHCl}_{3} / \mathrm{MeOH}^{9}: 1\right)$ to afford $0.13 \mathrm{~g}(50 \%)$ of 3 as a colourless oil. ${ }^{1} \mathrm{H}$ NMR (500 MHz, CD $\left.{ }_{3} \mathrm{OD}\right) 7.11$ (1 H, d, 3.1), 4.69 (1 H, dd, 7.5, 2.7), 3.71 (2 H, t, 6.4), 2.70 (1 H, m), 2.43 (1 H, dtd, 10.5, 7.9, 5.0), 2.27 (1 H, m), 2.10 (1 H, ddt, 14.3, 10.5, 7.5), 1.87 (1 H, m), 1.76 (1 H, td, 13.2, 6.4), 1.69 (1 H, dddd, 14.3, 7.5, 5.0, 2.7), 1.65 (1 H, m), 1.18 (1 H, m), $1.10(1 \mathrm{H}, \mathrm{m}) .{ }^{13} \mathrm{C} \mathrm{NMR}\left(125 \mathrm{MHz}, \mathrm{CD}_{3} \mathrm{OD}\right) \delta 172.2,149.7,132.9,91.9,83.0,60.9,44.4,39.1,32.7,32.6,32.5$, 32.4. HRMS calcd for $\mathrm{C}_{12} \mathrm{H}_{16} \mathrm{O}_{4} \mathrm{Na}[\mathrm{M}+\mathrm{Na}]$ : 247.0946, found: 247.0932 .

rac-(2aS,4R,5aS,7S,7aR)-2a-Hydroxy-4-(2-hydroxyethyl)-7-phenyl-4,5,5a,6,7,7a-hexahydroindeno [1,7-bc] furan2(2aH)-one(4): 4 was prepared in the same way as $\mathbf{3}$, starting from $\mathbf{1 3 b}(0.13 \mathrm{~g}, 0.4 \mathrm{mmol})$. The crude product was purified by chromatography $\left(\mathrm{SiO}_{2}, \mathrm{CHCl}_{3} / \mathrm{MeOH} 9: 1\right)$ to afford $3(60 \mathrm{mg}, 73 \%)$ as a colourless oil. ${ }^{1} \mathrm{H}(500$ $\left.\mathrm{MHz} \mathrm{CDCl}_{3}\right) 7.24$ (2 H, t, 7.4), 7.17 (1 H, td, 7.4, 2.3), 7.12 (1 H, d, 3.4), 7.09 (2 H, dt, 7.4, 2.3), 4.82 (1 H, dd, 6.3, 1.0), 3.72 (2 H, m), 3.47 (1 H, dt, 13.2, 6.3), 2.78 (1 H, m), 2.56 (1 H, dddd, 12.0, 8.1, 6.4, 3.8), 2.32 (1 H, ddd, 13.5, 8.1, 7.8), 2.06 (1 H, dddd, 13.2, 6.4, 6.3, 1.0), 1.72 (2 H, m), 1.36 (1 H, td, 13.2, 12.0), 1.04 (1 H, ddd, 13.5, 12.0, 3.8). ${ }^{13} \mathrm{C}$ NMR (125 $\left.\mathrm{MHz}, \mathrm{CDCl}_{3}\right)$ 170.3, 148.4, 136.8, 131.4, 128.3, 128.1, 126.7, 90.9, 81.2, 59.8, 48.2, 42.2, 37.7, 37.4, 31.2, 30.1. HRMS calcd for $\mathrm{C}_{18} \mathrm{H}_{20} \mathrm{O}_{4} \mathrm{Na}[\mathrm{M}+\mathrm{Na}]$ : 323.1259, found: 323.1283 .

2-(-2a-Hydroxy-2-oxo-2,2a,4,5,5a,6,7,7a-octahydroindeno [1,7-bc]furan-4-yl)ethyl 6-(5-((3aS,4S,6aR)-2-oxohexahydro-1H-thieno [3,4-d]imidazol-4-yl)pentanamido)hexanoate(5): To a dried flask containing the $N-(+)-$ 
biotinyl-6-aminohexanoic acid (50 mg, $0.13 \mathrm{mmol}$ ) was added thionyl chloride $(0.50 \mathrm{ml}, 6.3 \mathrm{mmol})$ under a nitrogen atmosphere and the mixture was stirred for $40 \mathrm{~min}$ at room temperature. The excess thionyl chloride was subsequently removed under reduced pressure and the crude product was used directly in the next step. 3 (19.2 mg, $0.09 \mathrm{mmol}$ ) was dissolved in $1.5 \mathrm{ml}$ of freshly distilled MeCN and the previously prepared acid chloride dissolved in $1.5 \mathrm{ml} \mathrm{MeCN}$ was added dropwise under a nitrogen atmosphere. The reaction mixture was stirred for $5 \mathrm{~h}$ at room temperature and then concentrated under reduced pressure. The crude product was purified by chromatography $\left(\mathrm{SiO}_{2}, \mathrm{CHCl}_{3} / \mathrm{MeOH}\right.$ 97:3) to afford 5 (9 mg, 19\%). The two diastereomers have identical NMR data. ${ }^{1} \mathrm{H}\left(500 \mathrm{MHz}, \mathrm{CD}_{3} \mathrm{OD}\right) 7.11$ (1 H, d, 3.2), 4.70 (1 H, dd, 7.3, 2.4), 4.52 (1 H, dd, 7.8, 4.5), 4.33 (1 H, dd, 7.8, 4.5), 4.24 (2 H, m), 3.23 (1 H, m), 3.17 (2 H, t, 6.9), 2.94 (1 H, dd, 12.8, 4.5), 2.72 (1 H, d, 12.8 ), 2.66 (1 H, tdd, 12.2, 7.1, 3.2), 2.44 (1 H, dtd, 10.5, 7.5, 2.4), 2.35 (2 H, t, 7.8), 2.29 (1 H, m), 2.20 (2 H, t, 7.4$), 2.11$ (1 H, ddt, 14.5, 10.5, 7.3), 1.89 (1 H, td, 14.5, 7.5), 1.81 (1 H, m), 1.73 (1 H, m), 1.77 - 1.55 (7 H, m), 1.52 (2 H, dt, 12.2, 6.9), 1.44 (2 H, m), 1.35 (2 H, m), 1.16 (1 H, m), 1.09 (1 H, m). ${ }^{13} \mathrm{C} \mathrm{NMR}\left(125 \mathrm{MHz}, \mathrm{CD}_{3} \mathrm{OD}\right) \delta 176.2$, 175.4, 172.0, 166.2, 148.9, 133.4, 91.9, 83.0, 63.7, 63.6, 62.0, 57.1, 44.5, 41.1, 40.4, 36.9, 35.1, 35.0, 34.8, 32.9, 32.9, 32.7, 32.5, 30.2, 29.9, 29.6, 27.6, 27.1. HRMS calcd for $\mathrm{C}_{28} \mathrm{H}_{42} \mathrm{~N}_{3} \mathrm{O}_{7} \mathrm{~S}$ [M + H]: 564.2743, found: 564.2744 .

2-(-2a-Hydroxy-2-oxo-7-phenyl-2,2a,4,5,5a,6,7,7a-octahydroindeno [1,7-bc]furan-4-yl)ethyl 6-(5-((3aS,4S, 6aR)-2-oxohexahydro-1H-thieno [3,4-d]imidazol-4-yl)pentanamido)hexanoate(6): 6 was prepared and purified in the same way as 5, starting from $4(10 \mathrm{mg}, 0.033 \mathrm{mmol})$ to afford $6(9.7 \mathrm{mg}, 45 \%)$ as a colourless oil. The two diastereomers have identical NMR data. ${ }^{1} \mathrm{H}\left(500 \mathrm{MHz}, \mathrm{CD}_{3} \mathrm{OD}\right) 7.27$ (2 H, m), 7.20 (1 H, m), 7.17 (2 H, dd, 6.1, 2.7), 7.15 (1 H, s), 4.86 (1 H, d, 6.5), 4.47 (1 H, dd, 7.9, 4.8), 4.28 (1 H, m), 4.28 (2 H, dd, 13.1, 5.3), 3.58 (1 H, dt, 13.5, 6.5), 3.21 (1 H, m), 3.16 (2 H, dd, 8.9, 7.4), 2.92 (1 H, dt, 12.8, 4.8), 2.79 (1 H, m), 2.70 (1 H, dd, 12.8, 3.8), 2.62 (1 H, dddd, 10.0, 8.1, 6.5, 3.6), 2.36 (3 H, m), 2.19 (2 H, td, 7.4, 2.1), 2.09 (1 H, ddd, 13.5, 6.5, 5.5), 1.95 (1 H, td, 13.1, 6.2), 1.86 (1 H, m), 1.73 (1 H, m), 1.69 - 1.55 (6 H, m), 1.51 (2 H, m), 1.44 (2 H, m), 1.36 (2 H, m), 1.20 (1 H, ddd, 13.2, 8.1, 3.9). ${ }^{13} \mathrm{C}$ NMR (125 MHz, $\left.\mathrm{CD}_{3} \mathrm{OD}\right)$ 176.1, 175.4, 172.0, 166.3, 148.9, 138.9, 133.2, 129.7, 129.3, 127.8, 92.6, 82.7, 63.7, 63.5, 61.7, 57.2, 49.6, 43.6, 41.2, 40.3, 38.7, 37.0, 35.2, 35.0, 33.1, 30.82, 30.2, 29.9, 29.6, 27.6, 27.1, 25.9. HRMS calcd for $\mathrm{C}_{34} \mathrm{H}_{46} \mathrm{~N}_{3} \mathrm{O}_{7} \mathrm{~S}[\mathrm{M}+\mathrm{H}]$ : 640.3056, found: 640.3051 .

(S)-N-Methoxy- $N$-methyl-2-phenylpent-4-enamide(17):To a solution of (S)-2-phenylpent-4-enoic acid (16) (6.8 g, $38 \mathrm{mmol}$ ), prepared from phenylacetic acid (14) according to reference 16 and identical in all aspects with the reported compound, in dry $\mathrm{CH}_{2} \mathrm{Cl}_{2}(4 \mathrm{ml})$ was added freshly distilled $\mathrm{SOCl}_{2}(11.4 \mathrm{~g}, 96 \mathrm{mmol})$ at $0^{\circ} \mathrm{C}$. The resulting brown mixture was stirred overnight at room temperature, where after the volatiles were removed under reduced pressure. The acid chloride, obtained as a black solid (7.8 g), was then dissolved in $\mathrm{dry}_{\mathrm{CH}} \mathrm{Cl}_{2}$ $(40 \mathrm{ml})$ and cooled to $0^{\circ} \mathrm{C}$ before the addition of $\mathrm{N}$-methyl-O-methylhydroxylamine hydrochloride (4.3 g, 44 mmol) under $\mathrm{N}_{2}$. After stirring at $0^{\circ} \mathrm{C}$ for $2 \mathrm{~h}$, pyridine $(6.7 \mathrm{~g}, 84 \mathrm{mmol})$ was added and the mixture was stirred at room temperature overnight. The solvent was removed under vacuum, and the remaining pale yellow solid was dissolved in a 1:1mixture of $\mathrm{Et}_{2} \mathrm{O} / \mathrm{CH}_{2} \mathrm{Cl}_{2}(50 \mathrm{~mL})$ and washed with brine $(50 \mathrm{ml})$. The organic layer was dried over $\mathrm{MgSO}_{4}$, and the solvents were removed under vacuum. The crude product was purified using flash chromatography $\left(\mathrm{SiO}_{2}\right.$, heptane/EtOAc 8:2) to afford $3.06 \mathrm{~g}$ (37\% over two steps from 14 via 16) of 17 as a colourless oil. $[\alpha]_{\mathrm{D}}{ }^{20}+75.0\left(\right.$ c 0.2 in $\left.\mathrm{CDCl}_{3}\right) .{ }^{1} \mathrm{H}\left(400 \mathrm{MHz}, \mathrm{CDCl}_{3}\right) 7.37$ - $7.21(5 \mathrm{H}, \mathrm{m}), 5.75(1 \mathrm{H}$, ddt, J 17.0, 10.2, 6.9), 5.06 (1 H, ddd, J 17.0, 3.3, 1.5), 4.99 (1 H, ddd, J 10.2, 3.3, 1.0), 4.09 (1 H, m), 3.47 (3 H, s), 3.17 (3 $\mathrm{H}, \mathrm{s}), 2.85(1 \mathrm{H}, \mathrm{m}), 2.47(1 \mathrm{H}, \mathrm{m}) .{ }^{13} \mathrm{C}\left(100 \mathrm{MHz}, \mathrm{CDCl}_{3}\right)$ 177.60, 139.64, 136.12, 128.56, 128.17, 126.99, 116.56, 61.29, 51.20, 38.21, 32.26. HRMS calcd for $\mathrm{C}_{13} \mathrm{H}_{18} \mathrm{NO}_{2}$ [M + H]: 220.1338, found: 220.1343

(S)-4-Phenylhept-6-en-1-yn-3-one(18):To a solution of 17 (3.1 g, $14 \mathrm{mmol})$ in $20 \mathrm{ml}$ of dry THF at $-78^{\circ} \mathrm{C}$ was added dropwise a solution of ethynylmagnesium bromide (110 ml, $0.5 \mathrm{M}$ in THF, $55 \mathrm{mmol}$ ) under $\mathrm{N}_{2}$. The mixture was stirred at $-78^{\circ} \mathrm{C}$ for $30 \mathrm{~min}$ and then allowed to warm to room temperature overnight. The reaction was quenched with $70 \mathrm{ml}$ of $\mathrm{NH}_{4} \mathrm{Cl}$ (sat). The layers were separated and the aqueous phase was extracted 3 times with $\mathrm{Et}_{2} \mathrm{O}$. The combined organic extracts were dried over $\mathrm{MgSO}_{4}$ and concentrated under reduced pressure. Flash chromatography $\left(\mathrm{SiO}_{2}\right.$, heptane/EtOAc 7:3) afford 2.6 g (quantitative yield) of the corresponding ynone 18. $[\alpha]_{\mathrm{D}}{ }^{20}+73.3\left(c 0.3\right.$ in $\left.\mathrm{CDCl}_{3}\right) .{ }^{1} \mathrm{H}\left(400 \mathrm{MHz}, \mathrm{CDCl}_{3}\right) 7.37$ (2 H, td, J 8.0, 1.9), 7.32 (1 H, tt, J 8.0, 1.9), 7.27 (2 H, dd, J 8.0, 1.9), 5.70 (1 H, ddt, J 17.0, 10.2, 7.1), 5.08 (1 H, ddd, J 17.0, 3.1, 1.5), 5.02 (1 H, ddd, J 10.2, 3.1, 1.1), 3.86 (1 H, t, J 7.1), 3.19 (1 H, s), 2.93 (1 H, dtd, J 14.4, 7.1, 1.1), 2.56 (1 H, dtd, J 14.4, 7.1, 1.5). ${ }^{13} \mathrm{C}(100$ $\left.\mathrm{MHz}, \mathrm{CDCl}_{3}\right) 184.61,134.74,128.90,128.69,127.81,117.33,80.17,77.20,60.39$, 35.38.HRMS calcd for $\mathrm{C}_{13} \mathrm{H}_{13} \mathrm{O}[\mathrm{M}+\mathrm{H}]:$ 185.0961, found: 185.0960 .

(S)-4-Phenylhept-6-en-1-yn-3-ol(19):18 (3.4 g, $18 \mathrm{mmol})$ was dissolved in dry THF (100 ml) and cooled to 
$-78^{\circ} \mathrm{C}$ before the addition of DIBAL ( $46 \mathrm{ml}, 1 \mathrm{M}$ in THF) under $\mathrm{N}_{2}$. The reaction mixture was stirred for $3 \mathrm{~h}$ at $-78^{\circ} \mathrm{C}$ and then quenched by the addition of $3 \mathrm{ml}$ of $\mathrm{MeOH}$ and $20 \mathrm{ml}$ of a solution of $\mathrm{Na} / \mathrm{K}$ tartrate (sat), extracted with EtOAc (40 ml x 3), dried over $\mathrm{Na}_{2} \mathrm{SO}_{4}$ and concentrated under reduced pressure. 19 (3.2 g, 92\%) was obtained as a 1:0.24 diasteromeric mixture and used in the next step without further purification. Diastereomer a). ${ }^{1} \mathrm{H}\left(400 \mathrm{MHz}, \mathrm{CDCl}_{3}\right) 7.39$ - $7.28(5 \mathrm{H}, \mathrm{m}), 5.69$ (1 H, ddd, 17.1, 10.1, 5.8), 5.07 (1 H, ddd, J 17.1, 3.3, 1.5), 4.98 (1 H, ddt, J 10.1, 3.3, 1.1), 4.55 (1 H, dd, J 5.8, 2.2), 2.98 (1 H, dt, J 9.2, 5.8), 2.78 (1 H, ddd, J 14.4, 5.8, 1.5), 2.57 (1 H, dd, 14.4, 9.2, 1.1), 2.53 (1 H, d, J 2.2). ${ }^{13} \mathrm{C}\left(100 \mathrm{MHz}, \mathrm{CDCl}_{3}\right)$ 139.17, 135.99, 128.86, 128.41, 127.22, 116.97, 83.25, 74.73, 65.72, 51.66, 35.35. Diastereomer b). ${ }^{1} \mathrm{H}\left(400 \mathrm{MHz}, \mathrm{CDCl}_{3}\right) 7.39$ - 7.28 (5 H, m), 5.69 (1 H, ddd, 17.1, 10.1, 5.8), 5.09 (1 H, ddd, J 17.1, 3.3, 1.5), 4.98 (1 H, ddt, J 10.1, 3.3, 1.1), 4.59 (1 H, dd, J 5.8, 2.2), 3.03 (1 H, dt, J 9.2, 5.8), 2.78 (1 H, ddd, J 14.4, 5.8, 1.5), 2.57 (1 H, dd, 14.4, 9.2, 1.1), 2.49 (1 $\mathrm{H}, \mathrm{d}, \mathrm{J}$ 2.2). ${ }^{13} \mathrm{C}\left(100 \mathrm{MHz}, \mathrm{CDCl}_{3}\right)$ 139.02, 135.84, 129.19, 128.27, 128.00, 116.92, 83.25, 75.05, 65.58, 50.90, 35.29. HRMS calcd for $\mathrm{C}_{13} \mathrm{H}_{14} \mathrm{ONa}$ [M + Na]: 209.0942, found: 209.0946.

Methyl ((4S,Z)-4-phenyldeca-1,8-dien-6-yn-5-yl) carbonate(20): The Sonogashira reaction was performed in the corresponding way as when $\mathbf{8 a} / \mathbf{8 b}$ was transformed to $\mathbf{1 0 a} / \mathbf{1 0 b}$, starting from $\mathbf{1 9}$ (3.4 g, $18 \mathrm{mmol}$ ) and cis-1bromo-prop-1-ene (6.6 g, $55 \mathrm{mmol})$, and the crude product was used directly for the preparation of the dienyne carbonate 20 as described for 11a/11b. $20(0.70 \mathrm{~g}, 13 \%)$ was obtained as a 1:0.15 diastereomeric mixture after purification by flash chromatography $\left(\mathrm{Si}_{2} \mathrm{O}\right.$, heptane/ $\left.\mathrm{CH}_{2} \mathrm{Cl}_{2} 1: 1\right)$. Diasteromer $a .{ }^{1} \mathrm{H}\left(400 \mathrm{MHz}, \mathrm{CDCl}_{3}\right) 7.36$ 7.22 (5 H, m), 6.03 (1 H, dq, J 10.7, 6.9), 5.66 (1 H, ddt, J 17.2, 10.2, 7.0), 5.59 (1 H, dd, J 6.0, 1.9), 5.50 (1 H, ddd, 10.7, 1.7, 1.5), 5.03 (1 H, ddd, J 17.2, 3.4, 1.4), 4.96 (1 H, ddt, J 10.2, 3.4, 1.1), 3.76 (3 H, s), 3.14 (1 H, dt, J 6.0, 5.1), $2.77(1 \mathrm{H}, \mathrm{m}), 2.65(1 \mathrm{H}, \mathrm{m}), 1.82$ (3 H, dd, J 6.9, 1.7). $\delta$ C (100 MHz, $\left.\mathrm{CDCl}_{3}\right)$ 154.87, 140.19, 138.92, 135.46, 128.89, 128.25, 127.15, 116.99, 109.12, 88.69, 84.65, 71.89, 54.89, 49.70, 35.08, 16.05. Diasteromer b. ${ }^{1} \mathrm{H}\left(400 \mathrm{MHz}, \mathrm{CDCl}_{3}\right) 7.36$ - $7.22(5 \mathrm{H}, \mathrm{m}), 6.00$ (1 H, dq, J 10.7, 6.9), 5.66 (1 H, ddt, J 17.2, 10.2, 7.0), 5.59 (1 H, dd, J 6.0, 1.9), 5.45 (1 H, ddd, 10.7, 1.7, 1.5), 5.01 (1 H, ddd, J 17.2, 3.4, 1.4), 4.96 (1 H, ddt, J 10.2, 3.4, 1.1), 3.80 (3 H, s), 3.14 (1 H, dt, J 6.0, 5.1), $2.77(1 \mathrm{H}, \mathrm{m}), 2.65(1 \mathrm{H}, \mathrm{m}), 1.74$ (3 H, dd, J 6.9, 1.7). ${ }^{13} \mathrm{C}$ $\left(100 \mathrm{MHz}, \mathrm{CDCl}_{3}\right)$ 154.87, 139.97, 139.17, 135.46, 128.78, 128.19, 127.11, 116.96, 109.09, 88.69, 84.65, 71.89, 54.89, 49.41, 35.47, 15.95. HRMS calcd for $\mathrm{C}_{18} \mathrm{H}_{20} \mathrm{O}_{3} \mathrm{Na}$ [M + Na]: 307.1310, found: 307.1331

Methyl 6-methyl-(2R)-phenyl-2,6,7,7a-tetrahydro- $1 \mathrm{H}$-indene-4-carboxylate(21): The diene 21 was obtained following the same procedure as when 12a/12b was prepared from 11a/11b, starting with $\mathbf{2 0}(0.70 \mathrm{~g}, 2.4 \mathrm{mmol})$. $21(0.32 \mathrm{~g}, 48 \%)$ was obtained as a 1:0.7 mixture of two diasteromers as a yellow oil, after flash chromatography $\left(\mathrm{SiO}_{2}\right.$, heptane/Et $\left.\mathrm{Et}_{2} \mathrm{O} 95: 5\right)$. Diasteromer a). ${ }^{1} \mathrm{H}\left(400 \mathrm{MHz}, \mathrm{CDCl}_{3}\right) 7.35$ - 7.17 (5 H, m), 6.81 (1 H, t, J 2.8), 6.33 (1 H, t, J 2.7), 4.04 (1 H, dd, J 3.0, 1.6), 3.79 (3H, s), 2.98 (1 H, m), $2.65(1 \mathrm{H}, \mathrm{m}), 2.12(1 \mathrm{H}, \mathrm{m}), 2.06$ (1 H, t, J 5.4), 1.99 (1 H, dt, J 12.7, 9.6), 1.14 (3 H, dd, J 7.3, 5.7), 1.07 (1 H, m). ${ }^{13} \mathrm{C}\left(100 \mathrm{MHz}, \mathrm{CDCl}_{3}\right) 166.93$, 166.91, 147.73, 145.90, 138.18, 130.52, 128.34, 127.19, 125.96, 51.59, 50.32, 43.34, 39.69, 38.45, 32.92, 20.74. Diasteromer b). ${ }^{1} \mathrm{H}\left(400 \mathrm{MHz}, \mathrm{CDCl}_{3}\right) 7.35$ - $7.17(5 \mathrm{H}, \mathrm{m}), 6.81(1 \mathrm{H}, \mathrm{t}, \mathrm{J} 2.8), 6.41(1 \mathrm{H}, \mathrm{t}, \mathrm{J} 2.8), 4.00(1 \mathrm{H}$, ddt, J 10.5, 3.0, 1.6), 3.80 (3 H, s), 2.86 (1 H, ddt, J 13.0, 9.5, 2.8), 2.65 (1 H, m), 2.59 (1 H, dt, J 12.2, 7.1), 2.06 $\left(1 \mathrm{H}, \mathrm{t}, \mathrm{J}\right.$ 5.4), 1.37 (1 H, dt, J 12.3, 10.3), $1.16(3 \mathrm{H}, \mathrm{dd}, \mathrm{J} 7.3,5.7), 1.07(1 \mathrm{H}, \mathrm{m}) .{ }^{13} \mathrm{C}\left(100 \mathrm{MHz}, \mathrm{CDCl}_{3}\right)$ 166.93, 166.91, 147.60, 145.50, 138.00, 129.53, 128.36, 127.43, 126.11, 51.59, 51.27,44.66, 42.09, 38.34, 33.14, 20.83. HRMS calcd for $\mathrm{C}_{18} \mathrm{H}_{21} \mathrm{O}_{2}[\mathrm{M}+\mathrm{H}]: 269.1542$, found: 269.1550 .

(1aS,2S,3aS,5S,7aS)-Methyl 5-methyl-2-phenyl-1a,2,3,3a,4,5-hexahydroindeno [1,7a-b]oxirene-7-carboxylate (22):22 was prepared following the same procedure as when 13a/13b was prepared from 12a/12b, starting from $21(0.31 \mathrm{~g}, 1.17 \mathrm{mmol}) .22$ (0.14 g, 42\%) was obtained after flash chromatography $\left(\mathrm{SiO}_{2}\right.$, heptane/ $\left.\mathrm{Et}_{2} \mathrm{O} 85: 15\right)$.

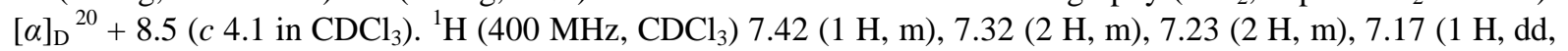
J 7.4, 2.2), $4.57(1 \mathrm{H}, \mathrm{s}), 3.75(3 \mathrm{H}, \mathrm{s}), 3.52(1 \mathrm{H}, \mathrm{m}), 2.56(1 \mathrm{H}, \mathrm{m}), 2.14(1 \mathrm{H}, \mathrm{m}), 1.94(1 \mathrm{H}, \mathrm{m}), 1.90(1 \mathrm{H}, \mathrm{m})$, $1.64(1 \mathrm{H}, \mathrm{m}), 1.40$ (1 H, ddd, J 14.8, 9.7, 7.5), 1.20 (3 H, dd, J 7.3). ${ }^{13} \mathrm{C}\left(100 \mathrm{MHz}, \mathrm{CDCl}_{3}\right)$ 165.40, 155.17, 141.93 , 128.61, 127.49, 126.58, 125.84, 66.40, 64.14, 62.15, 51.71, 44.67, 37.81, 33.76, 32.19, 20.40. HRMS calcd for $\mathrm{C}_{18} \mathrm{H}_{21} \mathrm{O}_{3}[\mathrm{M}+\mathrm{H}]: 285.1491$, found: 285.1472 .

(2aS,4S,5aS,7S,7aR)-2a-Hydroxy-4-methyl-7-phenyl-4,5,5a,6,7,7a-hexahydroindeno [1,7-bc]furan-2(2aH)-one(2):2 was prepared in the same way as when 13a/13b was transformed to 3/4, starting from $22(0.14 \mathrm{~g}, 0.5 \mathrm{mmol})$. The crude product was purified by chromatography $\left(\mathrm{SiO}_{2}\right.$, heptane/EtOAc 60:40.) to afford $2(30 \mathrm{mg}, 22 \%)$ as a colourless oil. $[\alpha]_{\mathrm{D}}{ }^{20}+59\left(\mathrm{c} 12.5 \mathrm{in} \mathrm{CDCl}_{3}\right) .{ }^{1} \mathrm{H}\left(400 \mathrm{MHz}, \mathrm{CDCl}_{3}\right) 7.30(2 \mathrm{H}, \mathrm{m}), 7.23(1 \mathrm{H}, \mathrm{m}), 7.13(2 \mathrm{H}, \mathrm{m})$, 7.10 (1 H, d, J 3.2), 4.90 (1 H, dd, J 6.7, 1.4), 3.52 (1 H, dt, J 13.4, 6.7), 2.77 (1 H, m), 2.62 (1 H, m), 2.36 (1 H, dt, J 14.0, 7.6), 2.12 (1 H, dtd, J 12.7, 6.7, 1.4), 1.45 (1 H, dd, J 13.4, 12.7), 1.25 (3 H, d, J 7.3), 1.12 (1 H, m). ${ }^{13} \mathrm{C}\left(100 \mathrm{MHz}, \mathrm{CDCl}_{3}\right)$ 170.0, 150.3, 136.8, 130.7, 128.4, 128.2, 126.8, 90.5, 81.3, 48.2, 42.2, 37.6, 31.6, 29.1, 
20.6. HRMS calcd for $\mathrm{C}_{17} \mathrm{H}_{19} \mathrm{O}_{3}[\mathrm{M}+\mathrm{H}]: 271.1334$, found: 271.1351

WST-1 cell proliferation assay

The functional activity of 1, 2, 3 and $\mathbf{4}$ were evaluated using a WST-1 proliferation assay with DU145 cells (ATCC, American Type Culture Collection, LGC Standards AB, Borås, Sweden) which expresses constitutively activated STAT3, as previously described [6]. In short, DU145 cells were cultured in 96-well plates (2000 cells/well in $200 \mu \mathrm{l}$ of medium) and allowed to set for $24 \mathrm{~h}$. The cells were treated with the test items for $72 \mathrm{~h}$. Samples were made in triplicate. $20 \mu \mathrm{lWST}-1$ solution (Roche Applied Science) was added per well and incubated at $37^{\circ} \mathrm{C}$ for $4 \mathrm{~h}$. The absorbance of each well was measured using a scanning multi-well spectrophotometer, ELISA reader at a wavelength of $450 \mathrm{~nm}$ and reference wavelength of $690 \mathrm{~nm}$. The results are presented as per cent of untreated control cells.

\section{Results and Discussion}

Our aim was to introduce a suitable functional group on the C-4 methyl group, as a handle to attach biotin via a linker. Initial attempts to introduce an alkyne or an azide to introduce the biotin group by "click chemistry" [12] failed. Instead a primary hydroxyl group was chosen as the functional group handle to attach biotin through an ester coupled linker, and the synthetic procedures for obtaining the galiellalactone analogues $\mathbf{3}$ and $\mathbf{4}$ as well as their biotinylated derivatives $\mathbf{5}$ and $\mathbf{6}$ are summarized in Scheme 1.
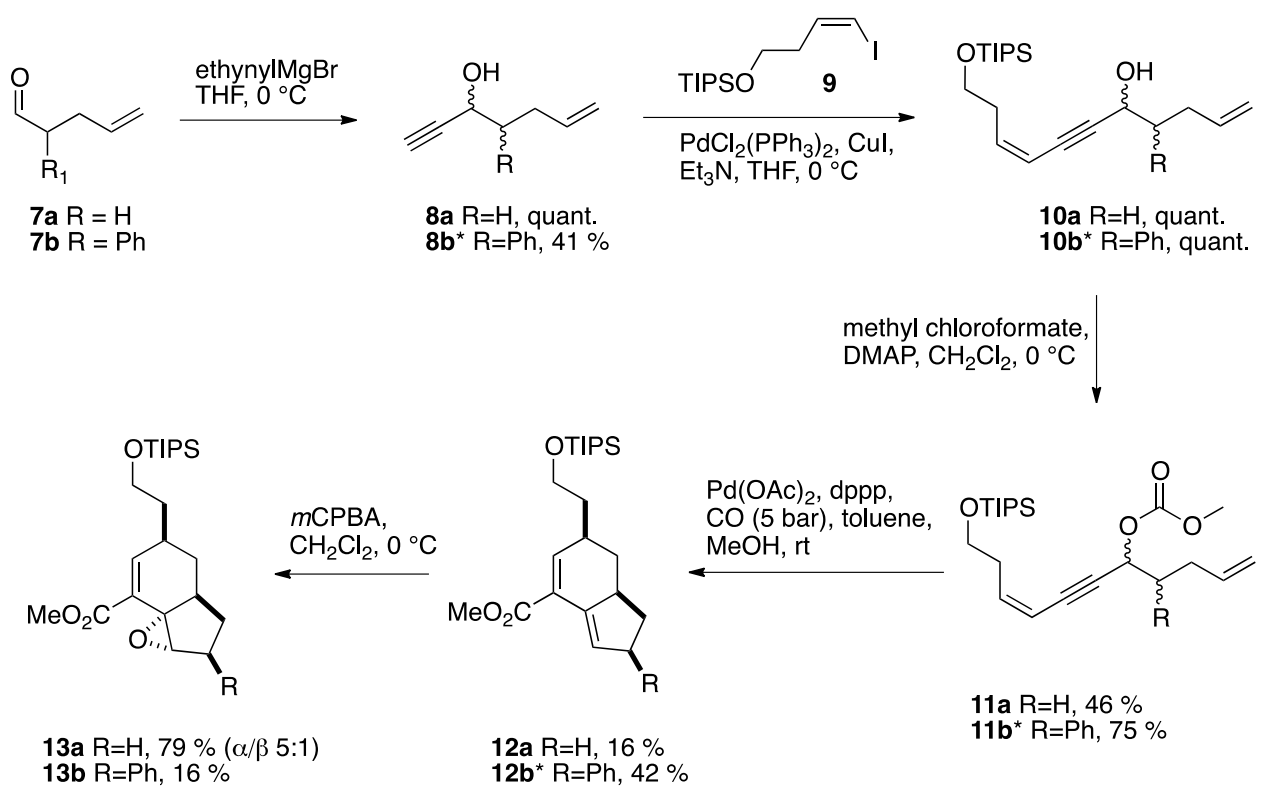
13b R=Ph, $16 \% \quad 12 \mathbf{b}^{\star} \mathrm{R}=\mathrm{Ph}, 42 \%$
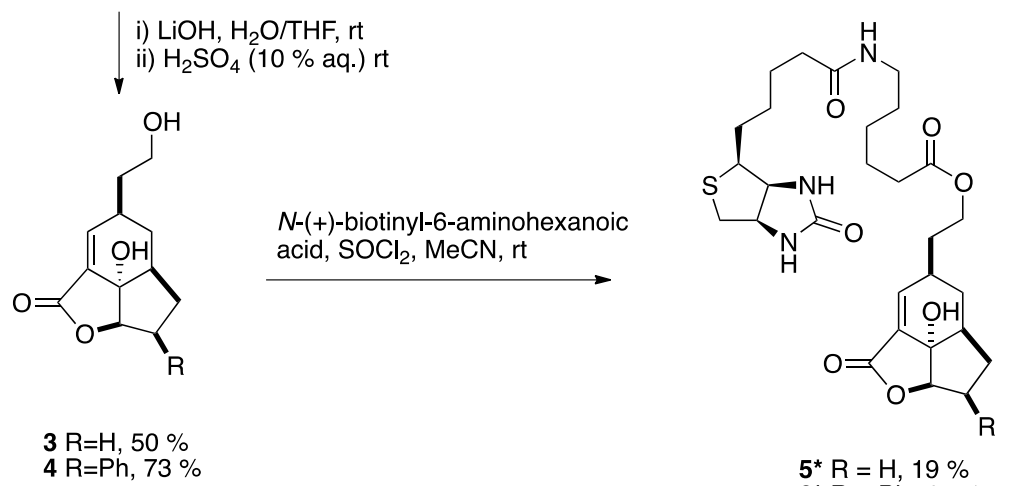

$5^{\star} \mathrm{R}=\mathrm{H}, 19 \%$

Scheme 1. Synthesis of 8-hydroxymethyl galiellalactone biotin 6-aminohexanoic acid amide ester (5) and 8-hydroxymethyl-7-phenyl galiellalactone biotin 6-aminohexanoic acid amide ester (6). "Intermediates $\mathbf{8 b}, \mathbf{1 0 b}, \mathbf{1 1 b}$ and $\mathbf{1 2 b}$ as well as the end products 5 and $\mathbf{6}$ were obtained as mixtures of diastereomers. 
Ethynyl magnesium bromide was added to 5-pentenal (7a) to give the propargylic alcohol 8a in a quantative yield. A Sonogashira coupling of the terminal alkyne of $\mathbf{8 a}$ with the known cis-iodoalkene $\mathbf{9}$ [13] containing a TIPS-protected hydroxyl group gave the alkenyne 10a. Thiswas treated with methyl chloroformate in the presence of DMAP to give the carbonate 11a, the key substrate for the tandem palladium catalyzed carbonylation/intramolecular Diels-Alder reaction. The ring forming transformation using $\mathrm{Pd}(\mathrm{OAc})_{2}$ and 1,3-bis(diphenylphosphino)propane under a $\mathrm{CO}$ atmosphere [8] gave the bicylic product 12a with the TIPS protected hydroxyl group intact. Regioselective epoxidation of the electron-rich double bond with $m$-CPBA gave the desired epoxide as a 5:1 $\alpha: \beta$ diastereomeric mixture, from which the desired isomer 13a could be isolated. 13a was subjected to the conditions bringing about the lactone formation [8], in this step the TIPS protecting group was lost and 8-hydroxymethyl galiellalactone $\mathbf{3}$ was isolated in 50\% yield. The synthesis of $\mathbf{3}$ proceeded with good or acceptable yields, except for the tandem palladium catalyzed carbonylation/intramolecular Diels-Alder reaction (from 11a to 12a), but this transformation gives poorer yields when the cyclopentene ring is unsubstituted. [8]

$N$-(+)-biotinyl-6-aminohexanoic acid had previously been described as a suitable reagent for making biotin conjugates of a biologically active compound [14]. However, attempts to couple $\mathrm{N}$-(+)-biotinyl-6-aminohexanoic acid using standard reagents for esterification failed, presumably because a base is used and the tricyclic galiellalactone system is sensitive to basic conditions. Galiellalactone (1) is relatively stable in acidic conditions and towards acid chlorides, so by first treating $N$-(+)-biotinyl-6-aminohexanoic acid with thionyl chloride to generate the corresponding acid chloride and then adding the alcohol $\mathbf{3}$ in acetonitrile the C-8 biotin conjugate 5 was prepared and could be isolated in $19 \%$ yield.

The corresponding biotin labeled 7-phenyl substituted derivative 6 was synthesized in an analogous manner. Starting from aldehyde $\mathbf{7 b}$, prepared by a DIBAL-H reduction of the corresponding 2-phenyl pent-4-ene acid ester, the key intermediate 11b could be obtained in three steps as a mixture of diastereomers. As we previously have observed, the tandem carbonylation/intramolecular Diels-Alder reaction gives a higher yield when a substituent in position 7 is present [8], and the cyclization of $\mathbf{1 1 b}$ proceeds in a $42 \%$ yield although the product is obtained as a mixture of two diastereomers. The epoxide $\mathbf{1 3 b}$ was isolated as a pure diastereomer but in a relatively poor yield, due to reduced stereoselectivity in the epoxidation, but the lactone formation to afford $\mathbf{4}$ runs smoother. The relative configuration of $\mathbf{3}$ as well as $\mathbf{4}$ was established by NMR NOESY experiments. Finally, the synthesis of $\mathbf{6}$ was accomplished by the esterification with $N$-(+)-biotinyl-6-aminohexanoic acid chloride.

To investigate the effect of a phenyl group in position 7, an asymmetric synthesis of 7-phenyl galiellalactone (2) was devised. The key objective was to obtain the substituted propargylic alcohol 19 with the absolute stereochemistry of C-4 set as shown in Scheme 2, as this would influence the stereochemistry of the subsequent stereocenters generated in the cyclization step. By applying a procedure developed for the enantioselective direct alkylation of arylacetic acids [15] using Koga's base (15) [16], (2S)-phenylpent-4-enoic acid (16) [17] was prepared from phenylacetic acid (14). By this procedure, 16 is obtained with $88 \%$ ee [17], and the material obtained here was identical to that reported. The acid $\mathbf{1 6}$ was converted to the corresponding Weinreb amide 17, which subsequently was reacted with ethynyl magnesium bromide to give the ynone $\mathbf{1 8}$. Reduction of the ketone with DIBAL gave the desired propargylic alcohol 19. The final steps from 19 via 20, 21, and 22 to 2 followed the procedure outlined in Scheme 2. 19 and $\mathbf{2 0}$ were obtained as mixtures of two diastereomers, in the ratios 1:0.24 and 1:0.15, but both diastereomers of $\mathbf{2 0}$ give the same product in the cyclization step. $\mathbf{2 1}$ was obtained as a mixture of two diastereomers in the ratio 1:0.7, the major is shown in Scheme 2 and this was readily epoxidized to 22.

To determine how the structural changes in 2, $\mathbf{3}$ and $\mathbf{4}$ affected their ability to block STAT3 signaling compared to galiellalactone (1), they were assayed for their ability to inhibit proliferation of DU145 prostate cancer cells which express active STAT3 in vitro, using a WST-1 assay (see Figure 2) [6]. The hydroxyl methyl analogue $\mathbf{3}$ had significantly reduced ability to inhibit proliferation $\left(\mathrm{GIC}_{50}=32 \mu \mathrm{M}\right)$ compared to $\mathbf{1}\left(\mathrm{GIC}_{50}=3.7\right.$ $\mu \mathrm{M}$ ), but the biological activity was restored when a phenyl group was added in position 7 as observed with analogue $4\left(\mathrm{GIC}_{50}=4.6 \mu \mathrm{M}\right)$. Compared with the natural product, the 7-phenyl analogue 2 has a slightly improved potency $\left(\mathrm{GIC}_{50}=2.9 \mu \mathrm{M}\right)$.

\section{Conclusion}

The biotinylated analogues $\mathbf{5}$ and $\mathbf{6}$ will be used in various biological studies to elucidate the mechanism of action of galiellalactone, starting with its effect on STAT3 signaling [5]. The fact that both $\mathbf{5}$ and $\mathbf{6}$ retain the 


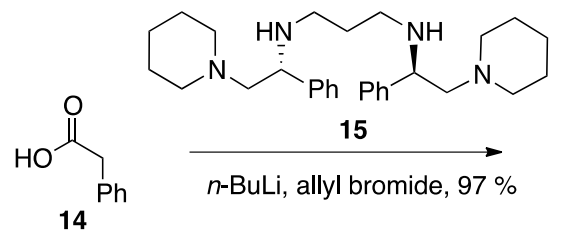

14<smiles>C=CCC(c1ccccc1)[C@H](C#C/C=C\C)OC(=O)OC</smiles>

20 *

i) cis-1-bromopropene, $\mathrm{PdCl}_{2}\left(\mathrm{PPH}_{3}\right)_{2}$, Cul, $\mathrm{Et}_{3} \mathrm{~N}, \mathrm{THF}, 0^{\circ} \mathrm{C}$

ii) methyl, chloroformate, DMAP, $\mathrm{CH}_{2} \mathrm{Cl}_{2}, 0^{\circ} \mathrm{C}$ $13 \%, 2$ steps

$\mathrm{Pd}(\mathrm{OAc}) 2, \mathrm{dppp}, \mathrm{CO}$

(5 bar), toluene, $\mathrm{MeOH}, \mathrm{rt}, 48 \%$<smiles>C=CCC(C(=O)O)c1ccccc1</smiles>

16 i. $\mathrm{SOCl}_{2}$

ii. $\mathrm{N}$-methyl-O-methylhydroxylamine $\mathrm{HCl}$, pyridine, $37 \%$<smiles>C=CC[C@H](C(=O)N(C)OC)c1ccccc1</smiles>

17 ethynylMgBr,
THF, $-78^{\circ} \mathrm{C}$<smiles>C#CC(O)C(CC=C)c1ccccc1</smiles>
$19^{*}$
THF, $-78^{\circ} \mathrm{C}$

$92 \%$

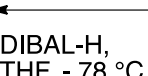<smiles>C#CC(=O)C(CC=C)c1ccccc1</smiles>

18 i) $\mathrm{LiOH}, \mathrm{H}_{2} \mathrm{O} / \mathrm{THF}$, rt

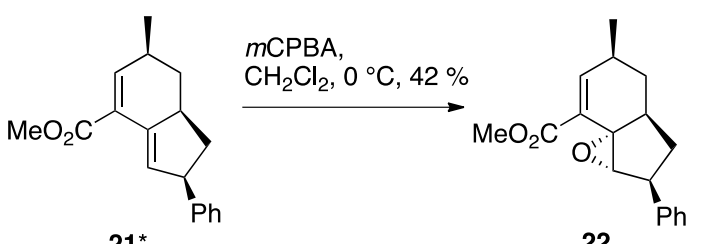

ii) $\mathrm{H}_{2} \mathrm{SO}_{4}(10 \%$ aq.),

rt, $22 \%$

2

Scheme 2. Asymmetric synthesis of 7-phenyl galiellalactone (2). *Intermediates 19, 20 and 21 were obtained as mixtures of diastereomers.

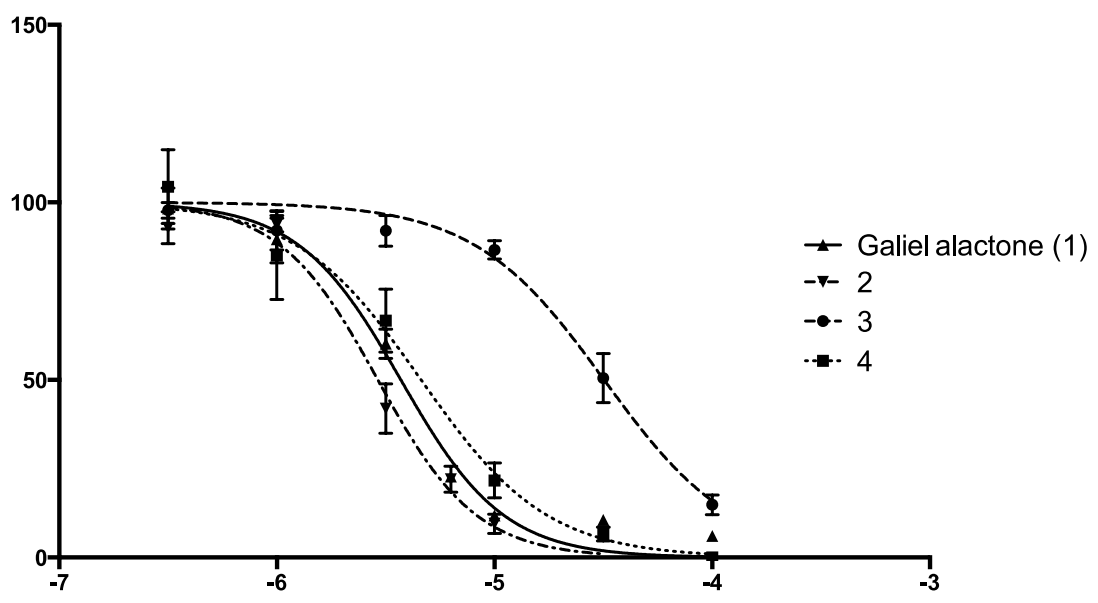

Figure 2. Cell proliferation dose response curve. Galiellalactone (1), 2, 3 and 4 inhibit proliferation of DU145 cells with GIC $_{50}$ values of $3.7 \mu \mathrm{M}, 2.9 \mu \mathrm{M}, 32 \mu \mathrm{M}$ and $4.6 \mu \mathrm{M}$, respectively after $72 \mathrm{~h}$. As discussed below, the biotinylated derivatives 5 and 6 retained the inhibitory effect.

ability to inhibit the proliferation of DU145 cells expressing constitutively active STAT3 (with the GIC ${ }_{50}$ values 6.6 and $14 \mu \mathrm{M}$, respectively, in the same WST-1 assay [5]) demonstrates that the attachment of biotin via a linker to position 4 of 1 produces cell permeable covalent STAT3 inhibitors that can be used as important tools for elucidating the mechanism of action of $\mathbf{1}$. With the biotinylated analogues synthesized in this work, in combination with biochemical methods, protein isolation and mass spectrometry, it was possible to show that $\mathbf{1}$ is a di- 
rect inhibitor of STAT3 by alkylating critical cysteine residues [6].

\section{Acknowledgements}

This work was supported by the Swedish Science Research Council.

\section{References}

[1] Peyser, N.D. and Grandis, J.R. (2013) Critical Analysis of the Potential for Targeting STAT3 in Human Malignancy. Journal of OncoTargets and Therapy, 6, 999-1010. http://dx.doi.org/10.1002/jcp.10364

[2] Calò, V., Migliavacca, M., Bazan, V., Macaluso, M., Buscemi, M., Gebbia, N. and Russo, A. (2003) STAT Proteins: From Normal Control of Cellular Events to Tumorigenesis. Journal of Cellular Physiology, 197, 157-168.

[3] Shodeinde, A.L. and Barton, B.E. (2012) Potential Use of STAT3 Inhibitors in Targeted Prostate Cancer Therapy: Future Prospects. OncoTargets and Therapy, 5, 119-125.

[4] Hellsten, R., Johansson, M., Dahlman, A., Sterner, O. and Bjartell, A. (2008) Galiellalactone is a Novel Therapeutic Candidate against Hormone-Refractory Prostate Cancer Expressing Activated Stat3. Prostate, 68, 269-280. http://dx.doi.org/10.1002/pros.20699

[5] Hellsten, R., Johansson, M., Dahlman, A., Sterner, O. and Bjartell, A. (2011) Galiellalactone Inhibits Stem Cell-Like ALDH-Positive Prostate Cancer Cells. PLoS One, 6, e22118. http://dx.doi.org/10.1371/journal.pone.0022118

[6] Don-Doncow, N., Escobar, Z., Johansson, M., Kjellstrom, S., Garcia, V., Munoz, E., Sterner, O., Bjartell, A. and Hellsten, R. (2014) Galiellalactone Is a Direct Inhibitor of STAT3 in Prostate Cancer Cells. Journal of Biological Chemistry, 289, 15969-15978. http://dx.doi.org/10.1074/jbc.M114.564252

[7] Johansson, M. (2002) Biosynthetic and SyntheticStudies of the Fungal Metabolite Gliellalactone. Ph.D. Dissertation, Bioorganic Chemistry, Lund University, Lund.

[8] Gidlof, R., Johansson, M. and Sterner, O. (2010) Tandem Pd-Catalyzed Carbonylation and Intramolecular Vinyl Allene Diels-Alder Reaction toward Galiellalactone Analogues. Organic Letters, 12, 5100-5103. http://dx.doi.org/10.1021/ol101989m

[9] Johansson, M., and Sterner, O. (2001) Synthesis of (+)-Galiellalactone. Absolute Configuration of Galiellalactone. Organic Letters, 3, 2843-2845. http://dx.doi.org/10.1021/ol016286+

[10] Johansson, M. and Sterner, O. (2002) Synthesis of (-)-Galiellalactone. The Journal of Antibiotics, 55, 663-665.

[11] Von Nussbaum, F., Hanke, R., Fahrig, T. and Benet-Buchholz, J. (2004) The High-Intrinsic Diels-Alder Reactivity of (-)-Galiellalactone; Generating Four Quaternary Carbon Centers under Mild Conditions. European Journal of Organic Chemistry, 2004, 2783-2790. http://dx.doi.org/10.1002/ejoc.200400137

[12] Best, M.D. (2009) Click Chemistry and Bioorthogonal Reactions: Unprecedented Selectivity in the Labeling of Biological Molecules. Biochemistry, 48, 6571-6584. http://dx.doi.org/10.1021/bi9007726

[13] La Cruz, T.E. and Rychnovsky, S.D. (2007) A Reductive Cyclization Approach to Attenol A. Journal of Organic Chemistry, 72, 2602-2611. http://dx.doi.org/10.1021/jo0626459

[14] Honda, T., Janosik, T., Honda, Y., Han, J., Liby, K.T., Williams, C.R., Couch, R.D., Anderson, A.C., Sporn, M.B. and Gribble, G.W. (2004) Design, Synthesis, and Biological Evaluation of Biotin Conjugates of 2-Cyano-3,12-dioxooleana1,9(11)-dien-28-oic Acid for the Isolation of the Protein Targets. Journal of Medicinal Chemistry, 47, 4923-4932. http://dx.doi.org/10.1021/jm049727e

[15] Stivala, C.E. and Zakarian, A. (2011) Highly Enantioselective Direct Alkylation of Arylacetic Acids with Chiral Lithium Amides as Traceless Auxiliaries. Journal of the American Chemical Society, 133, 11936-11939. http://dx.doi.org/10.1021/ja205107x

[16] Frizzle, M.J., Caille, S., Marshall, T.L., McRae, K., Nadeau, K., Guo, G., Wu, S., Martinelli, M.J. and Moniz, G.A. (2007) Dynamic Biphasic Counterion Exchange in a Configurationally Stable Aziridinium Ion: Efficient Synthesis and Isolation of a Koga $\mathrm{C}_{2}$-Symmetric Tetraamine Base. Organic Process Research \& Development, 11, 215-222. http://dx.doi.org/10.1021/op0602371

[17] Alliot, J., Gravel, E., Pillon, F., Buisson, D.A., Nicolas, M. and Doris, E. (2012) Enantioselective Synthesis of Levomilnacipran. Chemical Communications, 48, 8111-8113. http://dx.doi.org/10.1039/c2cc33743f 
Scientific Research Publishing (SCIRP) is one of the largest Open Access journal publishers. It is currently publishing more than 200 open access, online, peer-reviewed journals covering a wide range of academic disciplines. SCIRP serves the worldwide academic communities and contributes to the progress and application of science with its publication.

Other selected journals from SCIRP are listed as below. Submit your manuscript to us via either submit@scirp.org or Online Submission Portal.
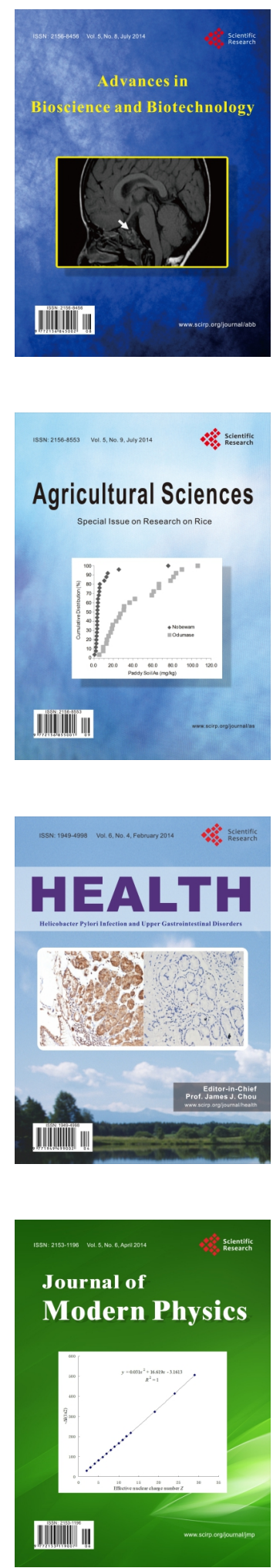
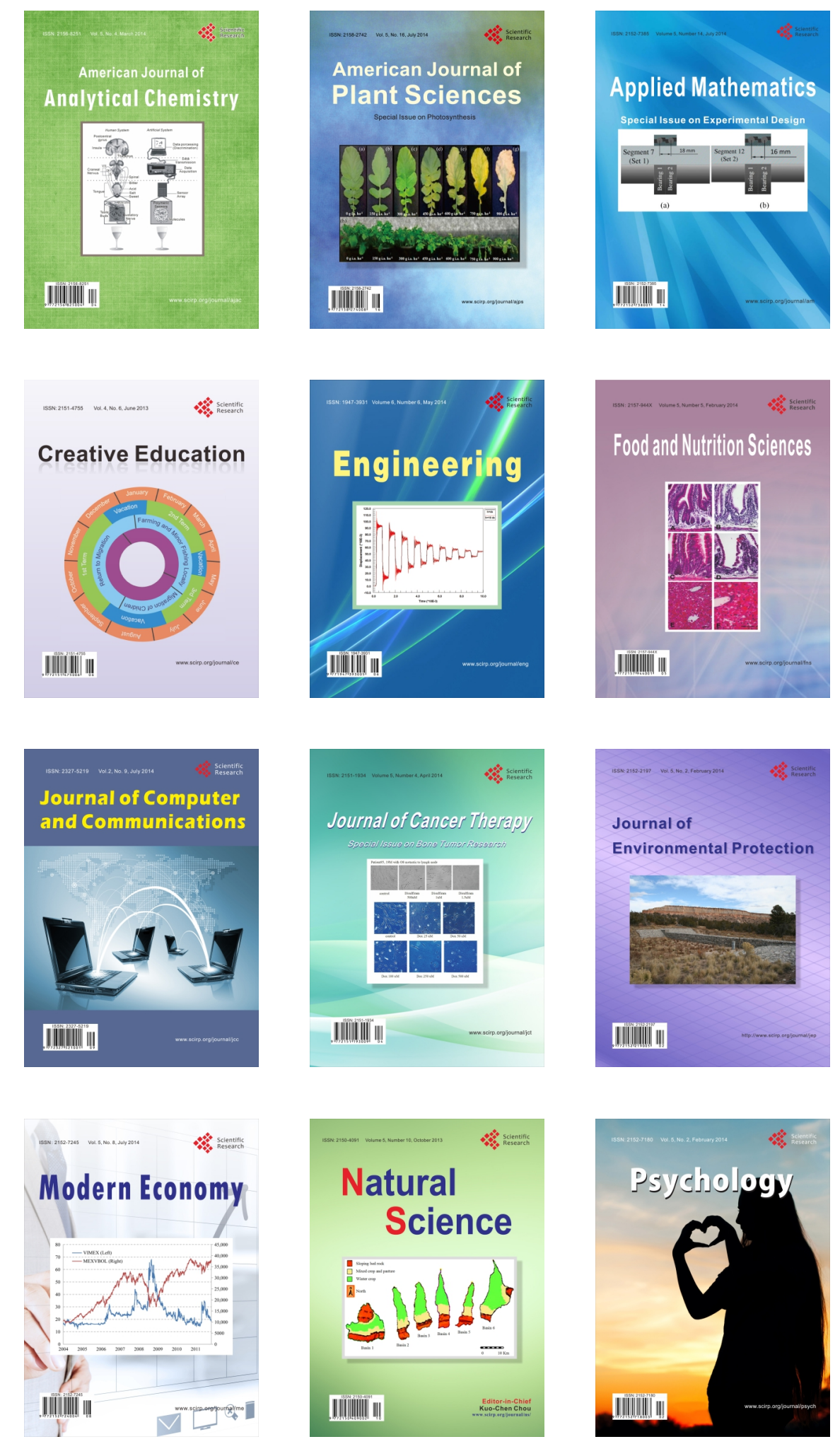